\title{
Effects of flow rate and temperature on cyclic gas exchange in tsetse flies (Diptera, Glossinidae)
}

\author{
John S. Terblanche ${ }^{\mathrm{a}, *}$, Steven L. Chown ${ }^{\mathrm{b}}$ \\ ${ }^{a}$ Department of Conservation Ecology and Entomology, Faculty of AgriSciences, Stellenbosch University, Private Bag X1, Matieland 7602, South Africa \\ ${ }^{\mathrm{b}}$ Centre for Invasion Biology, Department of Botany and Zoology, Stellenbosch University, Private Bag X1, Matieland 7602, South Africa
}

A R T I C L E I N F O

\section{Article history:}

Received 10 December 2008

Received in revised form 19 February 2009

Accepted 23 February 2009

\section{Keywords:}

Flow rate

Discontinuous gas exchange

Pattern

Respiratory cycles

Metabolic rate

Tsetse

Respirometry

\begin{abstract}
A B S T R A C T
Air flow rates may confound the investigation and classification of insect gas exchange patterns. Here we report the effects of flow rates $\left(50,100,200,400 \mathrm{ml} \mathrm{min}^{-1}\right)$ on gas exchange patterns in wild-caught Glossina morsitans morsitans from Zambia. At rest, G. m. morsitans generally showed continuous or cyclic gas exchange (CGE) but no evidence of discontinuous gas exchange (DGE). Flow rates had little influence on the ability to detect CGE in tsetse, at least in the present experimental setup and under these laboratory conditions. Importantly, faster flow rates resulted in similar gas exchange patterns to those identified at lower flower rates suggesting that G. m. morsitans did not show DGE which had been incorrectly identified as CGE at lower flow rates. While CGE cycle frequency was significantly different among the four flow rates $(p<0.05)$, the direction of effects was inconsistent. Indeed, inter-individual variation in CGE cycle frequency exceeded flow rate treatment variation. Using a laboratory colony of closely related, similar-sized G. morsitans centralis we subsequently investigated the effects of temperature, gender and feeding status on CGE pattern variation since these factors can influence insect metabolic rates. At $100 \mathrm{ml} \mathrm{min}{ }^{-1}$ CGE was typical of G. $m$. centralis at rest, although it was significantly more common in females than in males (57\% vs. $43 \%$ of 14 individuals tested per gender). In either sex, temperature $\left(20,24,28\right.$ and $\left.32{ }^{\circ} \mathrm{C}\right)$ had little influence on the number of individuals showing CGE. However, increases in metabolic rate with temperature were modulated largely by increases in burst volume and cycle frequency. This is unusual among insects showing CGE or DGE patterns because increases in metabolic rate are usually modulated by increases in frequency, but either no change or a decline in burst volume.
\end{abstract}

(c) 2009 Elsevier Ltd. All rights reserved.

\section{Introduction}

Insects at rest are characterised by at least three distinct gas exchange patterns. Continuous gas exchange is a pattern in which spiracles appear to open and close continuously and asynchronously, often associated with fairly high metabolic rates (e.g. Gibbs and Johnson, 2004). Cyclic gas exchange (CGE) shows distinct 'burst' and 'inter-burst' periods, spiracle behaviour appears fairly well co-ordinated, and at least some $\mathrm{CO}_{2}$ production is detectable even during the inter-burst period (e.g. Marais and Chown, 2003; Nespolo et al., 2007). Finally, discontinuous gas exchange (DGE) patterns, possibly the most curious and well characterised of insect gas exchange patterns (Chown et al., 2006), comprise three distinct periods when recording the insect's $\mathrm{CO}_{2}$ emission in a flowthrough, real-time system: a closed $(\mathrm{C})$ spiracle phase, a flutter $(\mathrm{F})$ phase and finally an open (O) phase (e.g. Hetz, 2007). Each of these

\footnotetext{
* Corresponding author. Tel.: +27 21808 4774; fax: +27 218082546 .

E-mail address: jst@sun.ac.za (J.S. Terblanche).
}

three periods is defined by distinct rates of exchange of each respiratory gas and DGE results in a partial temporal decoupling of $\mathrm{CO}_{2}$ release and $\mathrm{O}_{2}$ uptake (Lighton, 1996). Discontinuous gas exchange cycles were first thoroughly characterized in lepidopteran pupae, and have since been reported in a wide variety of adult insects and non-insect arthropods, and may have evolved independently at least five times within the Insecta (reviewed in Lighton, 1996; Marais et al., 2005; Chown et al., 2006).

While continuous (or possibly cyclic) gas exchange is thought to be basal in insects at rest (Marais et al., 2005; Clusella-Trullas and Chown, 2008), considerable variation in gas exchange patterns has been documented both within and among species (Lighton, 1998; Chown, 2001; Marais and Chown, 2003; Gibbs and Johnson, 2004; Marais et al., 2005; Nespolo et al., 2007; Woodman et al., 2007). The modification of the strongly periodic (cyclic) pattern, possibly through adaptive change to avoid excess water loss or oxidative damage (Hetz and Bradley, 2005; White et al., 2007; Terblanche et al., 2008a, but see also Lighton and Turner, 2008), is thought to have resulted in the more complex form of discontinuous gas exchange. Alternatively, the discontinuous pattern may initially 
have characterized the system at rest (as a consequence of interacting $\mathrm{CO}_{2}$ and $\mathrm{O}_{2}$ setpoints (Chown and Holter, 2000)) and subsequently have been selected to reduce water loss or oxidative damage (Chown and Nicolson, 2004; Terblanche et al., 2008a).

By contrast with these arguments, that tend to view the three patterns as relatively discrete entities, recent studies have suggested that the patterns may rather represent a continuum (e.g. Bradley, 2007). Moreover, in at least some cases this continuum may be confounded in its interpretation by inappropriate experimental methods, and particularly, low gas flow rates relative to cuvette size or the detection chamber size of the $\mathrm{CO}_{2}$ analyzer being used, which tend to reduce the resolution of the gas exchange pattern (Gray and Bradley, 2006, see also Bartholomew et al., 1981). Indeed, Gray and Bradley (2006) suggested that discontinuous gas exchange might be much more common (especially in small insects) than previously supposed because low flow rates favour an interpretation of the $\mathrm{VCO}_{2}$ trace as cyclic gas exchange. In fact, they also cautioned that strong relationships among temperature and metabolic rate and, in turn, metabolic rate and gas exchange characteristics, might also confound interpretation of gas exchange patterns. Typically, DGE yields the lowest, and continuous gas exchange the highest metabolic rates when patterns are compared within a species, although metabolic rates during CGE and DGE are frequently statistically indistinguishable (Vogt and Appel, 2000; Marais and Chown, 2003; Gibbs and Johnson, 2004; Gray and Chown, 2008).

In the context of previous work suggesting that cyclic gas exchange is phylogenetically basal, and that discontinuous gas exchange is uncommon or indeed absent in several, more derived insect orders, such as the Diptera (Marais et al., 2005), it is clear that additional work is required to determine the extent to which experimental artefacts might have influenced these conclusions. Here, we therefore firstly examine the influence of rate of air flow on gas exchange patterns in Glossina morsitans morsitans using wild-caught individuals in Zambia. Subsequently, using a laboratory-reared colony we investigate the effects of temperature, feeding status and gender on gas exchange patterns in a closely related sub-species, G. morsitans centralis, under controlled laboratory conditions. These latter factors are investigated as they have relatively well documented influences on metabolic rate in insects and therefore may influence gas exchange patterns. In the case of temperature, metabolic rate is strongly affected for most insect species including tsetse (Terblanche et al., 2005; Terblanche and Chown, 2007) with an acute increase in temperature resulting in higher resting metabolic rate (see Terblanche et al., 2005, 2009 for detailed discussion of these effects in tsetse). Feeding can also influence metabolic rate through the specific costs of digestion of a particular meal, also known as the heat increment of feeding or specific dynamic action (Bradley et al., 2003; Nespolo et al., 2005). Finally, gender might influence insect metabolic rates either through sexual-dimorphism or costs associated with reproduction (Terblanche et al., 2005). Although gas exchange patterns have been reported from the Diptera (Lehmann, 2001; Marais et al., 2005; Gray and Bradley, 2006), the order is relatively poorly investigated in this context. Moreover, although metabolic rate variation has been investigated in the Glossinidae, gas exchange patterns in tsetse are not well known, at least partly due to the fact that most early investigations made use of closed-system respirometry or radioisotope excretion rates with relatively poor temporal resolution to estimate metabolic rates (Rajagopal and Bursell, 1966; Hargrove and Coates, 1990), and that metabolic rate variation was the subject of most, more-recent investigations (e.g. Terblanche et al., 2004, 2005, 2009; Terblanche and Chown, 2007).

Therefore, the specific aims of this study are (1) to investigate the effects of flow rates on the pattern of gas exchange, and (2) to examine the influence of temperature, feeding status and gender on metabolic rate and gas exchange pattern modulation.

\section{Materials and methods}

\subsection{Flow-rate effects on wild-caught G. morsitans morsitans}

Using wild-caught G. m. morsitans in a field-laboratory established in Mfuwe, Zambia during October-November 2006 (see Terblanche et al., 2008b) we tested the effects of flow rates on the detection of gas exchange patterns. However, due to a strong, learned feeding behaviour which prevents wild tsetse from switching to artificial membrane feeding (Bouyer et al., 2007; Terblanche et al., 2008b) we were unable to hold these flies in the field-laboratory for longer than $\sim 48 \mathrm{~h}$ before severe starvation, and ultimately, death. In consequence, we were unable to undertake extensive comparisons of factors such as temperature, pregnancy, age and feeding effects in Zambia.

Here, we specifically undertook flow-through respirometry using the identical experimental setup described previously (Terblanche et al., 2004, 2005; Terblanche and Chown, 2007, see also Section 2.3 below), but with three key differences. First, only a single individual fly was run for an extended time period ( $\sim 4-8 \mathrm{~h}$ ) without switching the Sable Systems (SS) multiplexer through all seven respirometry cuvettes ( $5 \mathrm{ml}$ chamber volume). Second, respirometry recordings were undertaken at four flow rates, using rates both slower and faster than those typically employed in respirometry for insects of a similar size (50, 100, 200 and $400 \mathrm{ml} \mathrm{min}^{-1}$ ), and alternated through the four pre-selected flow rates in a random order within each individual fly. These four flow rates equate to a time constant of $6-0.75 \mathrm{~s}$. Finally, the respirometry was undertaken only at $24{ }^{\circ} \mathrm{C}$ and repeated on at least 19 individual flies. Due to field capture, flies used in these experiments were of an undetermined age, feeding and reproductive status. Regardless, the principal question addressed by this experiment (i.e. do flow rates affect the ability to detect gas exchange patterns) is not affected by this lack of information as the focus of this experiment is variation within individuals among the different flow rates. However, owing to several unknown factors (e.g. age, reproductive status, thermal history), which all can influence metabolic rate of tsetse (Terblanche et al., 2004, 2005; Terblanche and Chown, 2007), we refrained from undertaking detailed comparisons of resting metabolic rates in these wildcaught flies.

\subsection{Effects of temperature, feeding status and gender in a laboratory colony of G. morsitans centralis}

For the laboratory work investigating the effects of several factors on cyclic patterns and $\mathrm{VCO}_{2}$ modulation we chose a similarsized, closely related sub-species, G. morsitans centralis, which was readily available in sufficient numbers from a laboratory colony. Switching sub-species for this part of the work should also not alter the conclusions of the present study significantly since both $G$. morsitans centralis and G. m. morsitans are of a similar size and show similar $\mathrm{VCO}_{2}$ characteristics (e.g. RMR, metabolic rate-mass scaling relationships, metabolic rate-temperature relationships, Terblanche and Chown, 2007). Pupae of G. m. centralis (Diptera, Glossinidae) were obtained from the laboratory colony maintained at the Entomology Unit, FAO/IAEA Agriculture and Biotechnology Laboratory, Seibersdorf, International Atomic Energy Agency, Vienna, Austria which has been in culture for approximately 20-30 years (80-120 generations). Genetic diversity in closely related G. pallidipes and G. m. morsitans suggest that laboratory flies are usually within the range of field populations (Krafsur and Wohlford, 1999; Wohlford et al., 1999). For a different laboratory 
colony (from Singida, Tanzania) to the one used in the present study, gene diversity appeared to be relatively well-conserved among laboratory and field populations in G. m. centralis (Krafsur et al., 2001).

On arrival, pupae were immediately placed inside plastic containers and transferred to a climate chamber set to $24{ }^{\circ} \mathrm{C}$ $\left(24.6 \pm 2.5^{\circ} \mathrm{C}\right.$, photoperiod: 12:12 L:D). Relative humidity was regulated to $76 \%$ by means of saturated salt $(\mathrm{NaCl})$ solutions located within each container (Winston and Bates, 1960). Flies were transferred to mesh cages ( $10 \mathrm{~cm}$ diameter, $n=25-35$ per cage) after eclosion for use in various gender and feeding categories (as in Terblanche and Chown, 2007). All cages were located within closed, non-airtight plastic containers which also held $150 \mathrm{ml}$ jars containing the saturated salt solution. Feeding took place using a membrane-tray system every alternative day using bovine blood (similar to methods described previously in Terblanche et al., 2004, 2005), at which point container locations were randomized within climate chambers to preclude shelf effects.

Tsetse are exclusively haematophagous in both sexes, relatively long-lived flies ( $>3$ months as adults in the wild), which reproduce by adenotrophic viviparity (an introduction to tsetse ecology and biology is provided in Leak, 1999). Male and female flies were used in fed and fasted states for respirometry recordings. Flies used for respirometry approximately $1 \mathrm{~h}$ after a bloodmeal were considered 'fed', while flies which had not fed for at least $36 \mathrm{~h}$ were considered 'fasted'. Unmated females which had been separated from males at eclosion were used in the female category. All flies used in these experimental classes were reared in climate chambers set at $24-25{ }^{\circ} \mathrm{C}$ with the same photoperiod and humidity described for pupal rearing conditions (above). Flies used for respirometry experiments had received between 6 and 11 bloodmeals, and were therefore between 12 and 22 days old. Thus, they were also at an age when post-eclosion flight muscle developmental effects on metabolic rate are at a minimum (see Terblanche et al., 2004). All experimental and rearing facilities were housed in air-conditioned, quarantine-approved laboratories.

\subsection{Respirometry system}

Carbon dioxide production was recorded using flow-through respirometry similar to methods described previously (Terblanche et al., 2005; Terblanche and Chown, 2007). In brief, a LI-6262 (LiCor, Lincoln, USA) infra-red gas analyzer (IRGA) was connected to a Sable Systems International (Las Vegas, USA) eight channel multiplexer housed inside a Sable Systems PTC-1 temperaturecontrolled cabinet (accuracy $\pm 0.1{ }^{\circ} \mathrm{C}$ ). Compressed air, scrubbed of $\mathrm{CO}_{2}$ (using soda lime) and water (using silica gel and Drierite) was pushed through the multiplexer and the $5 \mathrm{ml}$ cuvettes housing the flies and regulated to $100 \mathrm{ml} \mathrm{min}^{-1}$ using a mass flow controller (Sierra Instruments, USA). The first seven channels of the multiplexer regulated the flow-through respirometry for seven individual flies and channel eight was used as an empty reference channel for $\mathrm{CO}_{2}$ and $\mathrm{H}_{2} \mathrm{O}$ baseline measurements. The multiplexer regulated airflow through channels 1 to 7 consecutively for $14 \mathrm{~min}$ at a time during one recording (sampling rate $=1 \mathrm{~s}$ ). While the active channel was recorded, an additional airflow line was set up to flush the other six inactive channels to prevent the build-up of $\mathrm{CO}_{2}$ and water vapour in the cuvettes. A thermocouple, connected to a Sable Systems TC1000 Thermocouple meter, was inserted into the first cuvette to measure the temperature inside a respirometry chamber containing an individual fly. The PTC- 1 temperature was manually set at 20, 24, $28,32{ }^{\circ} \mathrm{C}$ at the start of each test temperature's respirometry recording. The test temperatures were fixed in increasing order during all experiments. Respirometry recording was only started once the cuvette temperature was within $0.5^{\circ} \mathrm{C}$ of the target test temperature. A Sable Systems AD-1 electronic activity detector was connected to the first cuvette only and used to identify $\mathrm{CO}_{2}$ traces representative of stable, resting metabolic rate. Similar traces were then selected for all other flies to ensure that resting gas exchange characteristics were selected at a given temperature. All electronic units were connected to a desktop computer and Sable Systems DATACAN V software was used for instrument control and data acquisition, and to extract and analyze resting (inactive) metabolic rate data and cycle frequency. All data were baseline drift corrected prior to analyses. Mean burst emission volumes at each temperature were calculated from five bursts per individual only for individuals which showed cyclic gas exchange. These recordings were performed for males $(n=7)$ and females $(n=7)$ separately at each of the temperatures among the various experimental categories. This process was repeated twice for each of the experimental groups investigated to give $n=14$ for each gender $\times$ feeding status category. Flies were selected at random from all available cages for use in an experimental category to minimize any cage by treatment effect. Mass was recorded before and after respirometry recordings using a calibrated electronic balance (0.1 mg; FA 304T, Avery Berkel, EU).

\subsection{Statistical analyses}

Data were checked for normality using a Shapiro-Wilks test, and where necessary (metabolic rate, body mass, gas exchange cycle frequency and burst volume data) distributions were normalized by $\log _{10}$ transformation (Zar, 1999). The effects of different flow rates were analysed by extracting burst frequencies at each flow rate in individual flies showing cyclic gas exchange for at least six consecutive bursts in Expedata software. The raw, multiple cycle frequency values per individual were then analysed using a repeated measures ANOVA (implemented in SAS 9.0, SAS Institute, Cary, USA, proc mixed) with categorical factors for individuals and flow rates. Data are presented as means \pm standard error of the mean (S.E.) unless otherwise stated, and significance was set at $p=0.05$.

The effects of feeding status, gender, test temperature, mass, and interactions of the categorical variables on $\log _{10}$ metabolic rate are thoroughly explored in Terblanche and Chown (2007) and we therefore do not report these effects in full here for the sake of brevity. Here, we only explore the effects of feeding status, gender, test temperature, body mass and interactions on $\log _{10}$ cycle frequency and $\log _{10}$ burst volume (using general linear models (GLM)). Mean body mass, as determined from weighing before and after respirometry, of each individual was included as a covariate to ensure that its strong effect on metabolic rate and potentially cycle frequency was accounted for. All analyses were performed using Statistica version 7.0 (Statsoft, USA). Contingency tables were used to assess changes in proportions of individuals showing cyclic versus continuous gas exchange patterns among temperatures, feeding status and gender.

\section{Results}

\subsection{Flow-rate effects in G. m. morsitans}

Discontinuous gas exchange, as defined by a clearly distinguishable $\mathrm{C}-$, F-, and O-period, was never recorded at any flow rate across the range $50-400 \mathrm{ml} \mathrm{min}^{-1}$. Individuals of G. m. morsitans were classified as either showing cyclic or continuous gas exchange (following Marais et al., 2005). Because $\mathrm{VCO}_{2}$ did not reach zero in any of the recorded traces under these conditions it appears that the spiracles rarely closed completely, or if they did so, then only for very short periods (Fig. 1).

Flow rates of $50-400 \mathrm{ml} \mathrm{min}^{-1}$ had little influence on the ability to detect cyclic gas exchange in tsetse, at least in the present experimental setup (Fig. 1). There appeared to be a significant effect 



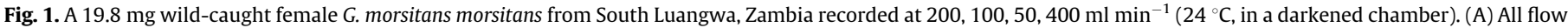

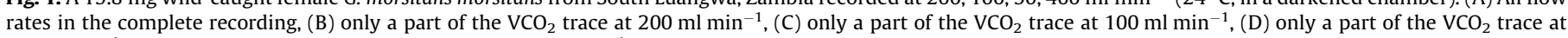
$50 \mathrm{ml} \mathrm{min}^{-1}$ and (E) only a part of the $\mathrm{VCO}_{2}$ trace at $400 \mathrm{ml} \mathrm{min}^{-1}$.

of flow rate on the number of individuals showing CGE. For example, at $400 \mathrm{ml} \mathrm{min}^{-1} 6 / 17$ individuals tested showed CGE while at $50 \mathrm{ml} \mathrm{min}^{-1} 12 / 19$ showed CGE. However, this variation in the proportion of CGE versus non-CGE individuals was not significant $\left(\chi^{2}=2.79, p=0.095\right)$. Importantly, flies generally showed similar cyclic gas exchange patterns at faster flow rates (e.g. Fig. 1) suggesting that G. m. morsitans did not show discontinuous gas exchange which had been incorrectly identified as a cyclic gas exchange pattern under lower flow rate conditions (Fig. 2).

In individuals showing CGE, cycle frequency was significantly different among the four flow rates (repeated measures ANOVA, $\left.F_{3,10}=4.49, p=0.031\right)$. However, the direction of effects was inconsistent: the lowest cycle frequencies were detected at $200 \mathrm{ml} \mathrm{min}^{-1}$ and the fastest at $100 \mathrm{ml} \mathrm{min}^{-1}$ flow rates (Fig. 3). In addition, individual flies differed significantly across all flow rates tested (repeated measures ANOVA, $F_{10,10}=32.36, p<0.0001$ ) suggesting that inter-individual variation is greater than interflow rate variation.
3.2. Effects of temperature, gender and feeding status on cyclic gas exchange pattern in $G$. $m$. centralis

Discontinuous gas exchange, as defined by a clearly distinguishable C-, F-, and O-period, was never recorded at $100 \mathrm{ml} \mathrm{min}^{-1}$ and individuals of G. m. centralis were classified as either showing cyclic or continuous gas exchange (following Marais et al., 2005). Because $\mathrm{VCO}_{2}$ did not reach zero in any of the recorded traces at the temporal resolution used, it appears that the spiracles rarely closed completely, or if they did, only did so for very short periods (Fig. 4A-D).

In laboratory-reared G. $m$. centralis at least $40 \%$ of the individuals recorded showed cyclic gas exchange, although the extent to which this took place was variable among temperatures (Table 1). Across all temperatures, the proportion of individuals showing cyclic gas exchange was greater in females than in male flies ( $57 \%$ vs. $\left.43 \% ; \chi^{2}=26.06 ; p<0.0001\right)$. By contrast, the proportion of individuals showing cyclic gas exchange did not 


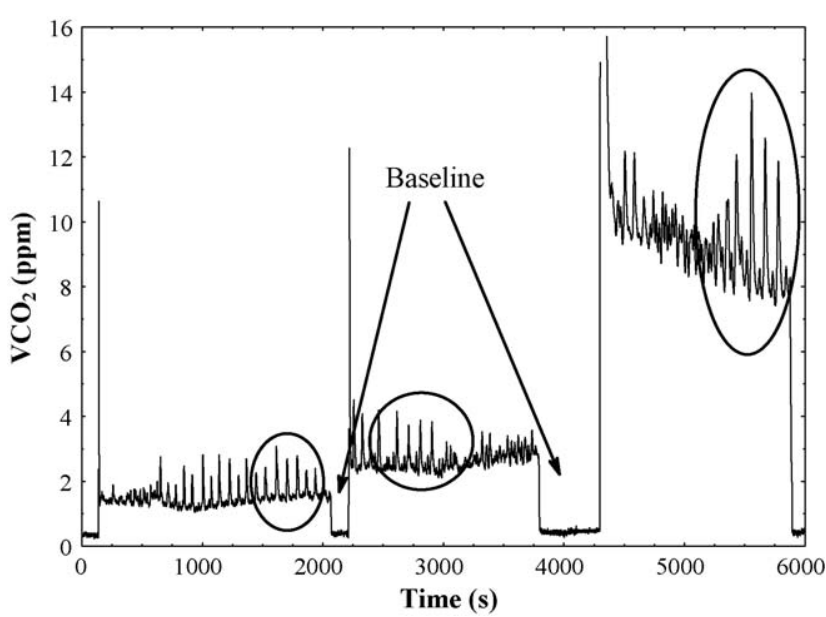

Fig. 2. Raw $\mathrm{VCO}_{2}$ recording from a $20.5 \mathrm{mg}$ female $\mathrm{G}$. $\mathrm{m}$. morsitans using 400,200 and $50 \mathrm{ml} \mathrm{min}{ }^{-1}$ flow rates. Mean cycle frequency for data extracted from each of the circled portions of the trace: $12.11 \pm 1.90 \mathrm{mHz}$ at $400 \mathrm{ml} \mathrm{min}^{-1}, 11.04 \pm$ $1.34 \mathrm{mHz}$ at $200 \mathrm{ml} \mathrm{min}^{-1}$ and $11.09 \pm 1.89 \mathrm{mHz}$ at $50 \mathrm{ml} \mathrm{min}^{-1}$.

differ between fasted and fed flies (65\% vs. 75\%; $\chi^{2}=2.18$; $p=0.16$ ). Furthermore, within either males or females, temperature did not alter the proportion of individuals showing cyclic gas exchange in a consistent direction (Table $1 ; p>0.05$ ).

Temperature, but not body mass, had a strong positive effect on cycle frequency (Table 2; Fig. 1A-D). Gas exchange cycle frequency did not differ between the genders nor between fed and unfed groups (Tables 1 and 2). No interactive effects of gender and feeding status on cycle frequency were found either (Table 2). By contrast, burst volume covaried positively with temperature, body mass, cycle frequency and feeding status, while gender had no effect thereon (Table 3). Nonetheless, the interaction between
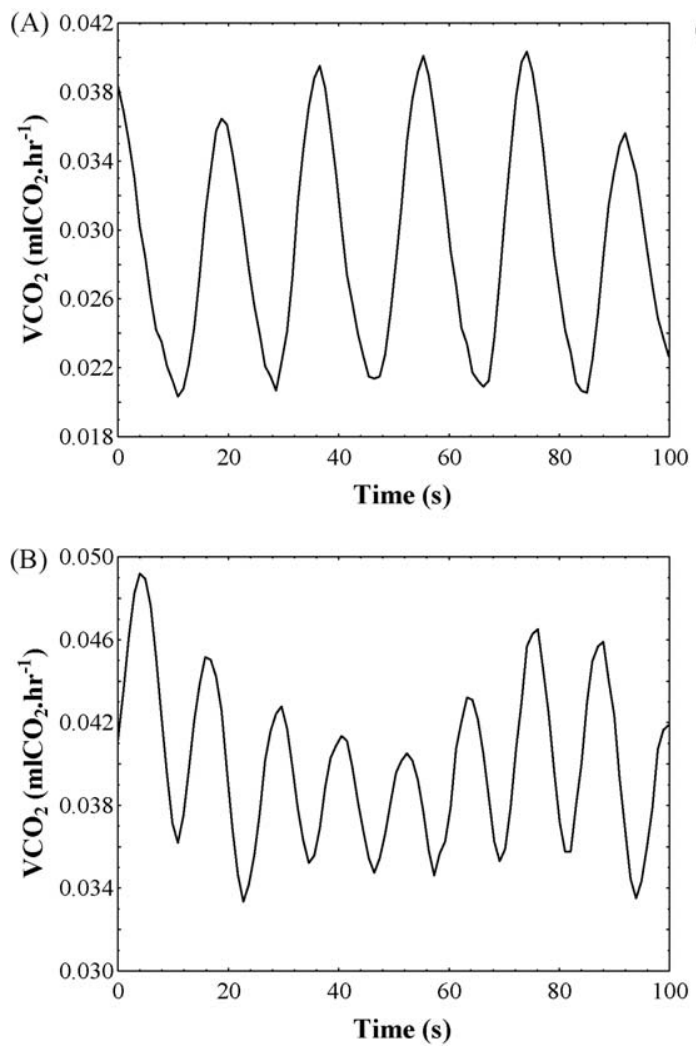

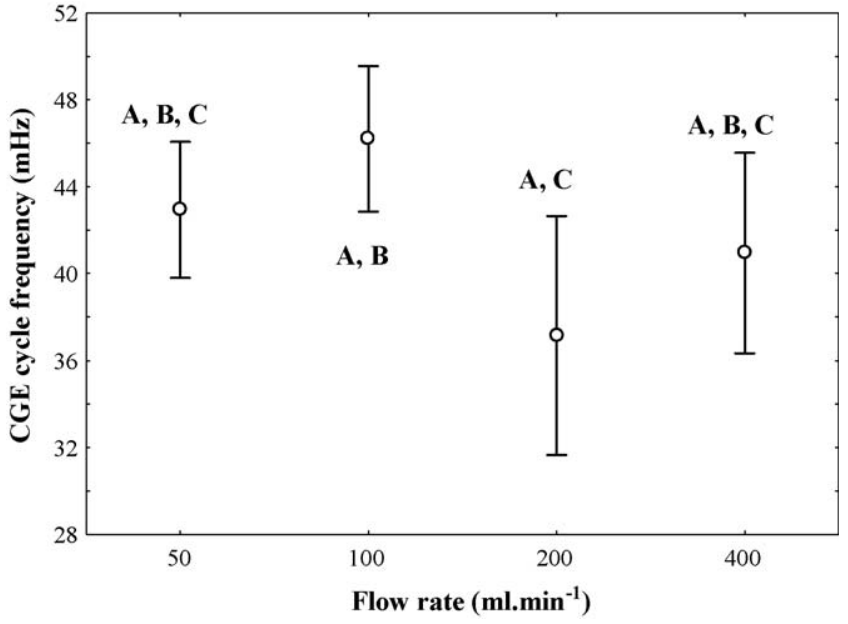

Fig. 3. The effect of flow rates (in $\mathrm{ml} \mathrm{min}^{-1}$ ) on resting cyclic gas exchange (CGE) frequency (in $\mathrm{mHz}$ ) at $24^{\circ} \mathrm{C}$ in wild-caught G. m. morsitans (for full results, see text).

gender and feeding status was significant, as might be expected if changes in $\mathrm{VCO}_{2}$ were modulated differently among males and females in different feeding states. Indeed, increases in metabolic rate with temperature were mostly a consequence of changes both in burst volume and cycle frequency, except in fasted males where variation in cycle frequency was not significant (Table 4).

\section{Discussion}

\subsection{Patterns of gas exchange in Glossina}

Few studies have directly investigated the effects of flow rates on insect gas exchange patterns, either in terms of the proportion
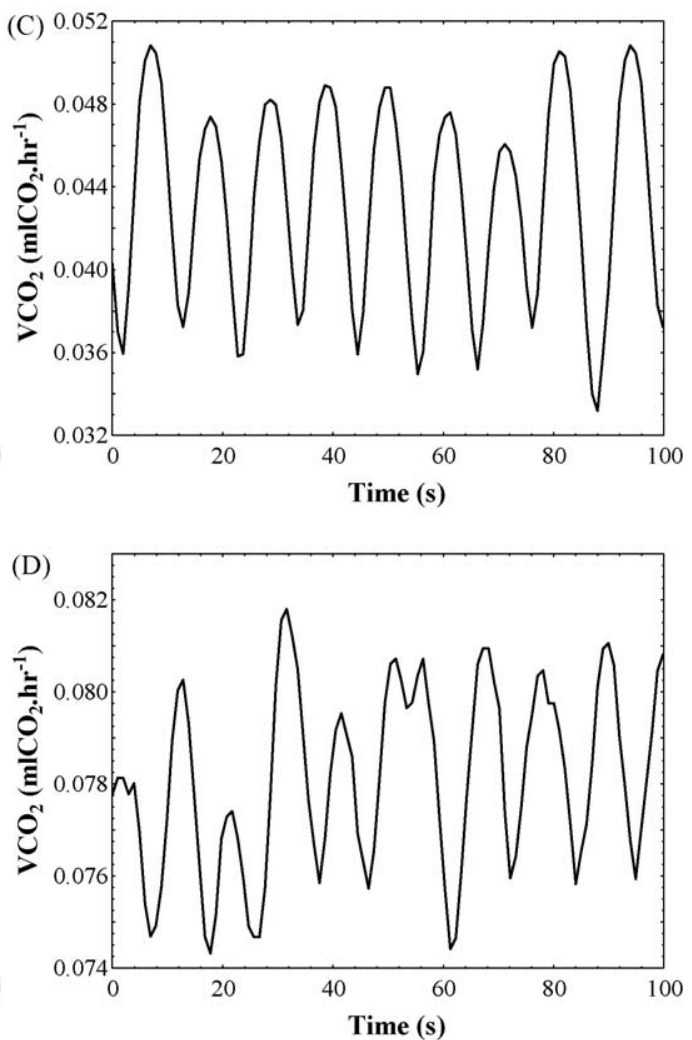

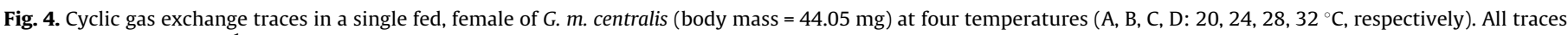
obtained at $100 \mathrm{ml} \mathrm{min}^{-1}$ flow rate with a $1 \mathrm{~s}$ sampling interval in a darkened temperature-controlled chamber. 
Table 1

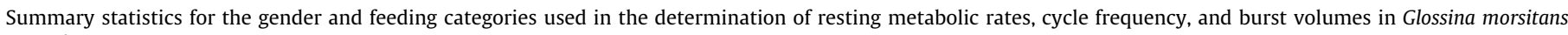
centralis.

\begin{tabular}{|c|c|c|c|c|c|c|}
\hline Gender & Temperature $\left({ }^{\circ} \mathrm{C}\right)$ & Feeding state & Mass (mg) & $\mathrm{VCO}_{2}\left(\mu \mathrm{lh}^{-1}\right)$ & Frequency $(\mathrm{mHz})$ & Burst volume $\left(\mu \mathrm{CO}_{2}\right)$ \\
\hline \multirow[t]{8}{*}{ Male } & \multirow[t]{2}{*}{20} & Fed & $29.58 \pm 1.66(14)$ & $13.93 \pm 0.86$ & $58.59 \pm 3.23(7)$ & $257.0 \pm 32.8(7)$ \\
\hline & & Fasted & $22.72 \pm 1.41(14)$ & $17.76 \pm 2.23(14)$ & $54.56 \pm 6.82(6)$ & $723.0 \pm 129.7$ \\
\hline & \multirow[t]{2}{*}{24} & Fed & & $19.46 \pm 0.86(14)$ & $64.29 \pm 6.31(8)$ & $320.9 \pm 34.0(8)$ \\
\hline & & Fasted & & $19.78 \pm 3.11(14)$ & $54.54 \pm 2.56(4)$ & $792.0 \pm 186.3$ \\
\hline & \multirow[t]{2}{*}{28} & Fed & & $28.75 \pm 1.60$ & $74.08 \pm 5.64(6)$ & $438.8 \pm 32.6(5)$ \\
\hline & & Fasted & & $27.43 \pm 3.79(14)$ & $54.38 \pm 3.41(8)$ & $514.3 \pm 53.23$ \\
\hline & \multirow[t]{2}{*}{32} & Fed & & $40.94 \pm 1.74$ & $71.10 \pm 9.73(7)$ & $724.2 \pm 81.5(7)$ \\
\hline & & Fasted & & $33.22 \pm 3.90(14)$ & $60.56 \pm 5.06(6)$ & $724.7 \pm 121.0$ \\
\hline \multirow[t]{8}{*}{ Female } & \multirow[t]{2}{*}{20} & Fed & $37.53 \pm 2.29(14)$ & $21.51 \pm 2.02(14)$ & $58.72 \pm 2.97(12)$ & $395.4 \pm 45.1(12)$ \\
\hline & & Fasted & $29.28 \pm 1.96(14)$ & $17.58 \pm 2.40$ & $55.17 \pm 3.08(10)$ & $349.1 \pm 67.9(10)$ \\
\hline & \multirow[t]{2}{*}{24} & Fed & & $30.68 \pm 3.97(14)$ & $73.19 \pm 6.68(12)$ & $582.5 \pm 143.1$ \\
\hline & & Fasted & & $27.34 \pm 3.86(14)$ & $58.61 \pm 3.65(9)$ & $523.7 \pm 87.2(9)$ \\
\hline & \multirow[t]{2}{*}{28} & Fed & & $43.15 \pm 4.35(14)$ & $72.05 \pm 9.50(11)$ & $687.2 \pm 128.3(11)$ \\
\hline & & Fasted & & $35.51 \pm 4.94(14)$ & $69.35 \pm 4.97(9)$ & $564.8 \pm 85.5(9)$ \\
\hline & \multirow[t]{2}{*}{32} & Fed & & $56.35 \pm 4.51(14)$ & $80.48 \pm 7.01(11)$ & $857.9 \pm 112.4(11)$ \\
\hline & & Fasted & & $43.18 \pm 4.66(14)$ & $71.25 \pm 3.42(11)$ & $777.7 \pm 74.9(10)$ \\
\hline
\end{tabular}

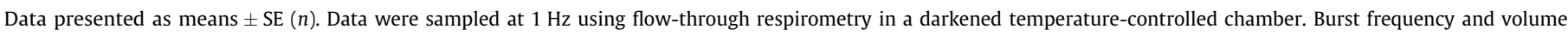

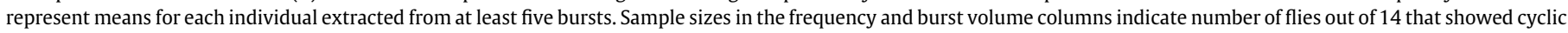
gas exchange.

Table 2

Results of a general linear model (GLM) analysis of gas exchange cycle frequency $\left(\log _{10} \mathrm{~Hz}\right)$ in Glossina morsitans centralis.

\begin{tabular}{lrlcc}
\hline Effect & DF & MS & $F$ & $p$-value \\
\hline Intercept & 1 & 0.807710 & 43.685 & $<0.0001$ \\
Temperature & 1 & 0.161051 & 8.741 & $<0.005$ \\
Log $_{10}$ mass & 1 & 0.004703 & 0.254 & 0.615 \\
Gender & 1 & 0.023161 & 1.253 & 0.265 \\
Feeding status & 1 & 0.048662 & 2.632 & 0.107 \\
Gender $\times$ feeding status & 1 & 0.018880 & 1.021 & 0.314 \\
Error & 131 & 0.018489 & & \\
\hline
\end{tabular}

Temperature and body mass were treated as continuous variables, while gender and feeding status were considered fixed effects. DF= degrees of freedom; $\mathrm{MS}=$ mean squares
Table 3

Results of a GLM analysis of burst volume $\left(\log _{10} \mathrm{mlCO}_{2}\right)$ in Glossina morsitans centralis estimated from $\mathrm{CO}_{2}$-production.

\begin{tabular}{lrllc}
\hline Effect & DF & MS & $F$ & $p$-value \\
\hline Intercept & 1 & 0.009719 & 0.5497 & 0.460 \\
Temperature & 1 & 2.571603 & 145.4486 & $<0.0001$ \\
Log $_{10}$ mass & 1 & 1.836646 & 103.8798 & $<0.0001$ \\
Log $_{10}$ frequency & 1 & 0.535501 & 30.2877 & $<0.0001$ \\
Gender & 1 & 0.059459 & 3.3630 & 0.069 \\
Feeding status & 1 & 0.438947 & 24.8266 & $<0.0001$ \\
Gender $\times$ feeding status & 1 & 0.137696 & 7.7880 & $<0.01$ \\
Error & 122 & 0.017680 & & \\
\hline
\end{tabular}

Temperature, body mass and frequency were treated as continuous variables, while gender and feeding status were considered fixed effects. DF = degrees of freedom; MS $=$ mean squares.

Table 4

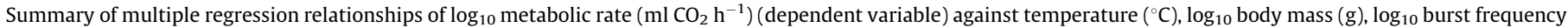
$(\mathrm{Hz})$ and $\log _{10}$ burst volume $\left(\mathrm{ml} \mathrm{CO}_{2}\right)$ (independent variables) within the experimental classes investigated for Glossina morsitans centralis.

\begin{tabular}{|c|c|c|c|c|c|c|}
\hline Category & Variable & Slope \pm SE & $r^{2}$ & $t$-value & $\mathrm{DF}$ & $p$ \\
\hline Males fed & $\begin{array}{l}\text { Intercept } \\
\text { Temperature } \\
\log _{10} \text { mass } \\
\log _{10} \text { burst frequency } \\
\log _{10} \text { burst volume }\end{array}$ & $\begin{array}{r}-1.3181 \pm 0.2545 \\
0.0170 \pm 0.0059 \\
0.0188 \pm 0.1465 \\
0.4093 \pm 0.1040 \\
0.5651 \pm 0.1232\end{array}$ & 0.938 & $\begin{array}{c}-5.179 \\
2.900 \\
0.128 \\
3.934 \\
4.586 \\
82.822^{\mathrm{a}}\end{array}$ & $\begin{array}{c}22 \\
22 \\
22 \\
22 \\
22 \\
4,22\end{array}$ & $\begin{aligned} &< 0.0001 \\
&< 0.01 \\
& 0.899 \\
&< 0.001 \\
&<0.001 \\
&<0.0001\end{aligned}$ \\
\hline Males fasted & $\begin{array}{l}\text { Intercept } \\
\text { Temperature } \\
\log _{10} \text { mass } \\
\log _{10} \text { burst frequency } \\
\log _{10} \text { burst volume }\end{array}$ & $\begin{array}{l}0.3316 \pm 0.4077 \\
0.0123 \pm 0.0056 \\
0.9701 \pm 0.3251 \\
0.4440 \pm 0.2455 \\
0.4362 \pm 0.1757\end{array}$ & 0.867 & $\begin{array}{c}0.813 \\
2.204 \\
2.984 \\
1.809 \\
2.483 \\
21.246^{\mathrm{a}}\end{array}$ & $\begin{array}{l}13 \\
13 \\
13 \\
13 \\
13 \\
4,13\end{array}$ & $\begin{aligned} & 0.431 \\
< & 0.05 \\
< & 0.05 \\
& 0.094 \\
< & 0.05 \\
< & 0.0001\end{aligned}$ \\
\hline Females fed & $\begin{array}{l}\text { Intercept } \\
\text { Temperature } \\
\log _{10} \text { mass } \\
\log _{10} \text { burst frequency } \\
\log _{10} \text { burst volume }\end{array}$ & $\begin{array}{r}-0.4729 \pm 0.2115 \\
0.0214 \pm 0.0037 \\
0.8100 \pm 0.1666 \\
0.2368 \pm 0.0758 \\
0.4175 \pm 0.0833\end{array}$ & 0.886 & $\begin{array}{r}-2.236 \\
5.705 \\
4.863 \\
3.124 \\
5.013 \\
79.939^{\mathrm{a}}\end{array}$ & $\begin{array}{c}41 \\
41 \\
41 \\
41 \\
41 \\
4,41\end{array}$ & $\begin{array}{l}<0.05 \\
<0.0001 \\
<0.0001 \\
<0.0001 \\
<0.005 \\
<0.0001\end{array}$ \\
\hline Females fasted & $\begin{array}{l}\text { Intercept } \\
\text { Temperature } \\
\log _{10} \text { mass } \\
\log _{10} \text { burst frequency } \\
\log _{10} \text { burst volume }\end{array}$ & $\begin{array}{l}0.3935 \pm 0.3193 \\
0.0042 \pm 0.0041 \\
0.5646 \pm 0.1665 \\
0.7812 \pm 0.1558 \\
0.8194 \pm 0.0871\end{array}$ &  & $\begin{array}{r}1.232 \\
1.041 \\
3.392 \\
5.014 \\
9.406 \\
137.440^{\mathrm{a}}\end{array}$ & $\begin{array}{c}33 \\
33 \\
33 \\
33 \\
33 \\
4,33\end{array}$ & $\begin{aligned} & 0.227 \\
& 0.306 \\
< & 0.005 \\
< & 0.0001 \\
< & 0.0001 \\
< & 0.0001\end{aligned}$ \\
\hline
\end{tabular}

\footnotetext{
${ }^{\text {a }}$ F-value.
} 
of individuals showing a particular pattern or with respect to cycle frequency (though see e.g. Rourke, 2000; Johnson and Gibbs, 2004). One of the recent studies to highlight the effects of flow rates on gas exchange pattern determination (Gray and Bradley, 2006) suggested that flow rates can be a major confounding factor in this field. Indeed, Gray and Bradley (2006) argued that, at higher flow rates, mosquitoes showed a distinct closed spiracle phase which was not evident at lower flow rates. Despite the obvious lack of a flutter period or any clear demonstration that the apparent $C$ phase $\mathrm{VCO}_{2}$ of Culiseta inornata was statistically indistinguishable from the gas analyser's baseline $\mathrm{VCO}_{2}$, the authors concluded that DGE and CGE were in fact two manifestations of the same pattern. Unfortunately, Gray and Bradley's (2006) study only provides evidence that flow rates can potentially alter the form of cyclic gas exchange, and not the characterization of the pattern as CGE or DGE. The latter requires clear identification of closed, flutter and open periods (e.g. Wobschall and Hetz, 2004; reviewed in Lighton, 1996; Chown et al., 2006), and no distinction between the flutter and closed periods was made by Gray and Bradley (2006). Thus, their argument that low flow rates had caused the mis-identification of DGE as CGE, and that Culiseta inornata shows DGE, requires further substantiation. In addition, the present study shows limited evidence of systematic effects of flow rates, either (i) in terms of mis-identifying CGE when in fact it should be DGE, (ii) the proportion of individuals showing CGE as opposed to continuous gas exchange under high and low flow rates, or finally, (iii) with regard to effects of experimental flow rates on the cycle frequency of CGE. This is likely a consequence of the fact that, in our system, the temporal resolution under the flow rates examined exceeded the time constant relative to the CGE burst frequencies.

While it is clear that flow rates can be a factor in the identification of gas exchange patterns for animals emitting very small amounts of $\mathrm{CO}_{2}$ (i.e. operating near or at the lower limit of a flow-through respirometry system) for many insects this potential problem should already have been detected and rectified during pilot trials. We therefore argue that for tsetse, which have reasonably average metabolic rate for their size among flies (Terblanche et al., 2004) in a 'typical' flow-through respirometry setup such as the one presently employed, the choice of flow rate is likely to have minimal influence on detection and 'correct' identification of gas exchange patterns, except where these rates are unrealistically low given information on the characteristics of flow-through gas exchange systems that has been available for some time (Bartholomew et al., 1981; see also Lighton, 2008 for a recent discussion). Moreover, using high flow rates may add confounding factors in the form of unusual behavioural patterns. Likewise, where time in the cuvette is reduced to eliminate the effects of desiccation, this might also prevent identification of the gas exchange pattern typical of the individual, or indeed characterization of variation in the patterns (Chown, 2001; Marais and Chown, 2003). Clearly a balance has to be struck between appropriate flow rates and appropriate experimental conditions. In this regard the work by Gray and Bradley (2006) is an exceptionally important reminder of the need to investigate time constants for flow-through systems.

Under the laboratory and respirometry conditions used both cyclic and continuous gas exchange were observed in $\mathrm{VCO}_{2}$ traces for G. m. centralis and G. m. morsitans, but at rest the former was the predominant pattern. Cyclic gas exchange may be a feature of morsitans group and perhaps of Glossina spp. more generally, given that at least half of the individuals examined in G. $m$. centralis and G. $m$. morsitans show some evidence thereof. Cyclic gas exchange has been reported from several other dipterans, including mosquitoes and vinegar flies (Lehmann et al., 2000; Gibbs et al., 2003; Gray and Bradley, 2003; Marais et al., 2005), and may be characteristic of the order, although many dipteran families have yet to be investigated. However, pattern types may have been misidentified in the past, particularly if the appropriate conditions were not carefully determined and controlled during respirometry.

\subsection{Effects of temperature, feeding and gender on pattern variation in Glossina}

Tsetse are clearly capable of modifying spiracle behaviour in response to changing environmental and physiological conditions (e.g. dehydration, Bursell, 1957). Changes in the proportion of individuals using cyclic as opposed to continuous gas exchange is seldom reported, but is being done so increasingly (e.g. Gibbs and Johnson, 2004; see also Clusella-Trullas and Chown, 2008). Here, the proportion of individuals expressing cyclic gas exchange differed between the sexes, but did not differ between feeding states or temperatures, suggesting that G. m. centralis does not have a state-dependent switch between patterns. In G. $m$. centralis the increase in $\mathrm{VCO}_{2}$ caused by higher temperature was modulated by increases in both burst volume and cycle frequency, except in fasted males, where only volume increased with temperature. The increase in burst volume with temperature is similar to the situation in the termite Incisitermes tabogae, in which a linear increase in burst volume with temperature was detected (Shelton and Appel, 2001). Thus, it appears that all insects with cyclic or discontinuous gas exchange modulate increases in metabolic rate by increasing cycle frequency. However, with a temperaturedriven increase in metabolic demand some show no changes in burst volume (Lighton and Wehner, 1993; Chappell and Rogowitz, 2000; Davis et al., 1999; Klok and Chown, 2005), others a decline (Schneiderman and Williams, 1955; Quinlan and Lighton, 1999; Vogt and Appel, 2000; Duncan and Dickman, 2001), and an increasing minority an increase in burst volume. The latter may well be characteristic only of species with cyclic gas exchange because, to date, this pattern has not been found among insects that show discontinuous gas exchange cycles. The increase in metabolic rate typical of feeding (e.g. Bradley et al., 2003; Nespolo et al., 2005) also appears to be modulated by an increase in burst volume and cycle frequency, and often discontinuous gas exchange is replaced by a continuous pattern (Duncan et al., 2002).

\subsection{Conclusion}

In conclusion, these data show that cyclic gas exchange is typical of G. morsitans under a variety of experimental conditions and perhaps of many Glossina spp. Furthermore, this study demonstrates the flow rates do not necessarily prevent accurate determination of gas exchange patterns under fairly standard conditions and it seems cyclic gas exchange in Glossina is therefore fairly robust to problems associated with variation in flow rate. Nevertheless, we strongly advocate pilot studies using a variety of flow rates to assess the suitability of a particular respirometry system for the determination of gas exchange patterns, as is typically undertaken by workers in this field (e.g. Socha et al., 2008). In sum, trade-offs among methodological issues (e.g. pattern change vs. dehydration tolerance when choosing a period for assessment) may always limit the utility of a particular approach in insect gas exchange physiology, which thus reemphasizes the importance of reporting study conditions in detail. This will also be particularly useful for large-scale metaanalyses of insect gas exchange patterns which are increasingly used to inform debates on the evolutionary origin of pattern variation across terrestrial arthropods and possible modulation of patterns in response to abiotic factors (e.g. Marais et al., 2005; White et al., 2007). Further work is required, however, to determine whether variation in gas exchange patterns (either in terms of cycle frequency or proportion of individuals showing a 
particular pattern) differs among Glossina species and whether this varies consistently with environmental moisture or temperature gradients.

\section{Acknowledgements}

We thank Elrike Marais and Emilie Gray for early discussions of this work. Jaco Klok, Jacques Deere, Susana Clusella-Trullas, Erika Nortje and Charlene Janion provided valuable logistic assistance and support at various stages during this project, and two referees provided useful comments on the ms. This work was funded by NRF Grant IFR2008071500012 to SLC. JST was supported by the Faculty of AgriSciences and Sub-Committee B funding during the writing of this manuscript. We are particularly grateful to Stefan K. Hetz for several stimulating discussions and the invitation to contribute to this special issue.

\section{References}

Bartholomew, G.A., Vleck, D., Vleck, C.M., 1981. Instantaneous measurements of oxygen consumption during pre-flight warm-up and post-flight cooling in sphingid and saturniid moths. Journal of Experimental Biology 90, 17-32.

Bouyer, J., Pruvot, M., Bengaly, Z., Guerin, P.M., Lancelot, R., 2007. Learning influences host choice in tsetse. Biology Letters 3, 113-116.

Bradley, T.J., 2007. Control of the respiratory pattern in insects. In: Roach, R.C., et al. (Eds.), Hypoxia and the Circulation. Springer, New York, pp. 215-224.

Bradley, T.J., Brethorst, L., Robinson, S., Hetz, S., 2003. Changes in the rate of $\mathrm{CO}_{2}$ release following feeding in the insect Rhodnius prolixus. Physiological and Biochemical Zoology 76, 302-309.

Bursell, E., 1957. Spiracular control of water loss in the tsetse fly. Proceedings of the Royal Entomological Society of London A 32, 21-29.

Chappell, M.A., Rogowitz, G.L., 2000. Mass, temperature and metabolic effects on discontinuous gas exchange cycles in Eucalyptus-boring beetles (Coleoptera: Cerambycidae). Journal of Experimental Biology 203, 3809-3820.

Chown, S.L., 2001. Physiological variation in insects: hierarchical levels and implications. Journal of Insect Physiology 47, 649-660.

Chown, S.L., Holter, P., 2000. Discontinuous gas exchange cycles in Aphodius fossor (Scarabaeidae): a test of hypotheses concerning origins and mechanisms. Journal of Experimental Biology 203, 397-403.

Chown, S.L., Nicolson, S.W., 2004. Insect Physiological Ecology. Mechanisms and Patterns. Oxford University Press, Oxford.

Chown, S.L., Gibbs, A.G., Hetz, S.K., Klok, C.J., Lighton, J.R.B., Marais, E., 2006. Discontinuous gas exchange in insects: a clarification of hypotheses and approaches. Physiological and Biochemical Zoology 79, 333-343.

Clusella-Trullas, S., Chown, S.L., 2008. Investigating onycophoran gas exchange and water balance as a means to inform current controversies in arthropod physiology. Journal of Experimental Biology 211, 3139-3146.

Davis, A.L.V., Chown, S.L., Scholtz, C.H., 1999. Discontinuous gas-exchange cycles in Scarabaeus dung beetles (Coleoptera: Scarabaeidae): mass-scaling and temperature dependence. Physiological and Biochemical Zoology 72, 555-565.

Duncan, F.D., Dickman, C.R., 2001. Respiratory patterns and metabolism in tenebrionid and carabid beetles from the Simpson Desert Australia. Oecologia 129, 509-517.

Duncan, F.D., Krasnov, B., McMaster, M., 2002. Novel case of a tenebrionid beetle using discontinuous gas exchange cycle when dehydrated. Physiological Entomology 27, 79-83.

Gibbs, A.G., Fukuzato, F., Matzkin, L.M., 2003. Evolution of water conservation mechanisms in Drosophila. Journal of Experimental Biology 206, 1183-1192.

Gibbs, A.G., Johnson, R.A., 2004. The role of discontinuous gas exchange in insects: the chthonic hypothesis does not hold water. Journal of Experimental Biology 207, 3477-3482.

Gray, E.M., Bradley, T.J., 2003. Metabolic rate in female Culex tarsalis (Diptera: Culicidae): age, size, activity, and feeding effects. Journal of Medical Entomology 40, 903-911.

Gray, E.M., Bradley, T.J., 2006. Evidence from mosquitoes suggests that cyclic gas exchange and discontinuous gas exchange are two manifestations of a single respiratory pattern. Journal of Experimental Biology 209, 1603-1611.

Gray, E.M., Chown, S.L., 2008. Bias, precision and accuracy in the estimation of cuticular and respiratory water loss: a case study from a highly variable cockroach, Perisphaeria sp. Journal of Insect Physiology 54, 169-179.

Hargrove, J.W., Coates, T.W., 1990. Metabolic rates of tsetse flies in the field as measured by the excretion of injected cesium. Physiological Entomology 15, 157-166.

Hetz, S.K., 2007. The role of the spiracles in gas exchange during development of Samia cynthia (Lepidoptera Saturniidae). Comparative Biochemistry and Physiology 148A, 743-754.

Hetz, S.K., Bradley, T.M., 2005. Insects breathe discontinuously to avoid oxygen toxicity. Nature 433, 516-519.
Johnson, R.A., Gibbs, A.G., 2004. Effect of mating stage on water balance, cuticular hydrocarbons and metabolism in the desert harvester ant, Pogonomyrmex barbatus. Journal of Insect Physiology 50, 943-953.

Klok, C.J., Chown, S.L., 2005. Temperature- and body mass-related variation in cyclic gas exchange characteristics and metabolic rate in seven weevil species: broader implications. Journal of Insect Physiology 51, 789-801.

Krafsur, E.S., Endsley, M.A., Wohlford, D.L., Griffiths, N.T., Allsopp, R., 2001. Genetic differentiation of Glossina morsitans centralis populations. Insect Molecular Biology 10, 387-395.

Krafsur, E.S., Wohlford, D.L., 1999. Breeding structure of Glossina pallidipes populations evaluated by mitochondrial variation. Journal of Heredity 90 , 635-642.

Leak, S.G.A., 1999. Tsetse Biology and Ecology: Their Role in the Epidemiology and Control of Trypanosomosis. CABI Publishing, New York.

Lehmann, F.-O., 2001. Matching spiracle opening to metabolic need during flight in Drosophila. Science 294, 1926-1929.

Lehmann, F.-O., Dickinson, M.H., Staunton, J., 2000. The scaling of carbon dioxide release and respiratory water loss in flying fruit flies (Drosophila spp.). Journal of Experimental Biology 203, 1613-1624.

Lighton, J.R.B., 1996. Discontinuous gas exchange in insects. Annual Review of Entomology 41, 309-324.

Lighton, J.R.B., 1998. Notes from underground: towards ultimate hypotheses of cyclic, discontinuous gas-exchange in tracheate arthropods. American Zoologist 38, 483-491.

Lighton, J.R.B., 2008. Measuring Metabolic Rates. A Manual For Scientists. Oxford University Press, Oxford.

Lighton, J.R.B., Turner, R.J., 2008. The hygric hypothesis does not hold water: abolition of discontinuous gas exchange cycles does not affect water loss in the ant Camponotus vicinus. Journal of Experimental Biology 211, 563-567.

Lighton, J.R.B., Wehner, R., 1993. Ventilation and respiratory metabolism in the thermophilic desert ant, Cataglyphis bicolor (Hymenoptera, Formicidae). Journal of Comparative Physiology B 163, 11-17.

Marais, E., Chown, S.L., 2003. Repeatability of standard metabolic rate and gas exchange characteristics in a highly variable cockroach, Perisphaeria sp. Journal of Experimental Biology 206, 4565-4574.

Marais, E., Terblanche, J.S., Klok, C.J., Chown, S.L., 2005. Insect gas exchange patterns: a phylogenetic perspective. Journal of Experimental Biology 208, 4495-4507.

Nespolo, R.F., Castañeda, L.E., Roff, D.A., 2005. The effect of fasting on activity and resting metabolism in the sand cricket, Gryllus firmus: a multivariate approach. Journal of Insect Physiology 51, 61-66.

Nespolo, R.F., Artacho, P., Castañeda, L.E., 2007. Cyclic gas-exchange in the Chilean red cricket: inter-individual variation and thermal dependence. Journal of Experimental Biology 210, 668-675.

Quinlan, M.C., Lighton, J.R.B., 1999. Respiratory physiology and water relations of three species of Pogonomyrmex harvester ants (Hymenoptera: Formicidae) Physiological Entomology 24, 293-302.

Rajagopal, P.K., Bursell, E., 1966. The respiratory metabolism of resting tsetse flies. Journal of Insect Physiology 12, 287-297.

Rourke, B.C., 2000. Geographic and altitudinal variation in water balance and metabolic rate in a California grasshopper, Melanoplus sanguinipes. Journal of Experimental Biology 203, 2699-2712.

Schneiderman, H.A., Williams, C.M., 1955. An experimental analysis of the discontinuous respiration of the cecropia silkworm. Biological Bulletin 109, 123-143.

Shelton, T.G., Appel, A.G., 2001. Cyclic $\mathrm{CO}_{2}$ release in Cryptotermes cavifrons Banks Incisitermes tabogae (Snyder) and I. minor (Hagen) (Isoptera: Kalotermitidae). Comparative Biochemistry and Physiology A 129, 681-693.

Socha, J.J., Lee, W.-K., Harrison, J.F., Waters, J.S., Fezzaa, K., Westneat, M.W., 2008. Correlated patterns of tracheal compression and convective gas exchange in a carabid beetle. Journal of Experimental Biology 211, 3409-3420.

Terblanche, J.S., Chown, S.L., 2007. The effects of temperature, body mass and feeding on metabolic rate in the tsetse fly Glossina morsitans centralis. Physiological Entomology 32, 175-180.

Terblanche, J.S., Klok, C.J., Chown, S.L., 2004. Metabolic rate variation in Glossina pallidipes (Diptera: Glossinidae): gender, ageing and repeatability. Journal of Insect Physiology 50, 419-428.

Terblanche, J.S., Klok, C.J., Chown, S.L., 2005. Temperature-dependence of metabolic rate in Glossina morsitans morsitans (Diptera, Glossinidae) does not vary with gender, age, feeding, pregnancy or acclimation. Journal of Insect Physiology 51, 861-870.

Terblanche, J.S., Marais, E., Hetz, S.K., Chown, S.L., 2008a. Control of discontinuous gas exchange in Samia cynthia: effects of atmospheric oxygen, carbon dioxide and moisture. Journal of Experimental Biology 211, 3272 3280.

Terblanche, J.S., Clusella-Trullas, S., Deere, J.A., Chown, S.L., 2008b. Thermal tolerance in a south-east African population of the tsetse fly Glossina pallidipes (Diptera, Glossinidae): implications for forecasting climate change impacts. Journal of Insect Physiology 54, 114-127.

Terblanche, J.S., Clusella-Trullas, S., Deere, J.A., Van Vuuren, B.J., Chown, S.L., 2009. Directional evolution of the slope of the metabolic rate-temperature relationship is correlated with climate. Physiological and Biochemical Zoology.

Vogt, J.T., Appel, A.G., 2000. Discontinuous gas exchange in the fire ant, Solenopsis invicta Buren: caste differences and temperature effects. Journal of Insect Physiology 46, 403-416. 
White, C.R., Blackburn, T.M., Terblanche, J.S., Marais, E., Gibernau, M., Chown, S.L., 2007. Evolutionary responses of discontinuous gas exchange in insects. Proceedings of the National Academy of Sciences USA 104, 8357-8361.

Winston, P.W., Bates, D.H., 1960. Saturated solutions for the control of humidity in biological research. Ecology 41, 232-237.

Wobschall, A., Hetz, S.K., 2004. Oxygen uptake by convection and diffusion in diapausing moth pupae (Attacus atlas). International Congress Series 1275, 157-164.
Wohlford, D.L., Krafsur, E.S., Griffiths, N.T., Marquez, J.G., Baker, M.D., 1999. Genetic differentiation of some Glossina morsitans morsitans populations. Medical and Veterinary Entomology 13, 377-385.

Woodman, J.D., Cooper, P.D., Haritos, V.S., 2007. Cyclic gas exchange in the giant burrowing cockroach, Macropanesthia rhinoceros: effect of oxygen tension and temperature. Journal of Insect Physiology 53, 497-504.

Zar, J.H., 1999. Biostatistical Analysis. Prentice-Hall, Inc, New Jersey. 